\title{
HLA-DRB1* 14 is a protective allele for multiple sclerosis in an admixed Colombian population
}

\section{OPEN}

Jaime Toro, MD, FAAN, FACP

David Cuellar-Giraldo, MD

Camilo Díaz-Cruz, MD

Lisseth-Estefania

Burbano, MD

Claudia-Marcela Guío, MD

Saúl Reyes, MD

Fabián Cortes, MSc

Simón Cárdenas-Robledo, $\mathrm{MD}$

Diana M. Narváez, MSc Wilmer Cárdenas, MSc Alexandra Porras, MSc María-Claudia Lattig, $\mathrm{PhD}$

Helena Groot de Restrepo, MSc

Correspondence to Dr. Toro: jtoro@uniandes.edu.co

Supplemental data at Neurology.org/nn

\section{ABSTRACT}

Objective: The aim of this study was to determine ancestry informative markers, mitochondrial DNA haplogroups, and the association between HLA-DRB1 alleles and multiple sclerosis (MS) in a group of patients from Bogotá, Colombia.

Methods: In this case-control study, genomic DNA was isolated and purified from blood samples. HLA-DRB1 allele genotyping was done using PCR. Mitochondrial hypervariable region 1 was amplified and haplogroups were determined using HaploGrep software. Genomic ancestry was estimated by genotyping a panel of ancestry informative markers. To test the association of $\mathrm{HLA}$ polymorphisms and MS, we ran separate multivariate logistic regression models. Bonferroni correction was used to account for multiple regression tests.

Results: A total of 100 patients with MS (mean age $40.4 \pm 12$ years; 70\% females) and 200 healthy controls (mean age $37.6 \pm 11$ years; $83.5 \%$ females) were included in the analysis. Ancestry proportions and haplogroup frequencies did not differ between patients and controls. HLA-DRB1*15 was present in $31 \%$ of cases and $13.5 \%$ of controls, whereas HLA-DRB1*14 was present in $5 \%$ of cases and $15.5 \%$ of controls. In the multivariate model, HLA-DRB1*15 was significantly associated with MS (odds ratio $[\mathrm{OR}]=3.05, \mathrm{p}<0.001$ ), whereas HLA-DRB1*14 was confirmed as a protective factor in our population (OR $=0.16, p=0.001)$.

Conclusions: This study provides evidence indicating that HLA-DRB1*15 allele confers susceptibility to MS and HLA-DRB1*14 allele exerts resistance to MS in a highly admixed population. This latter finding could partially explain the low prevalence of MS in Bogotá, Colombia. Neurol Neuroimmunol Neuroinflamm 2016;3:e192; doi: 10.1212/NXI.0000000000000192

\section{GLOSSARY}

AIM = ancestry informative marker; HVR1 = hypervariable region $1 ;$ HU-FSFB = Hospital Universitario Fundación Santa Fe de Bogotá; $\mathbf{M H C}=$ major histocompatibility complex; $\mathbf{M S}=$ multiple sclerosis; $\mathbf{m t D N A}=$ mitochondrial DNA; OR = odds ratio.

The most consistent genetic risk factor reported in multiple sclerosis (MS) is the HLADRB1*15 allele, which has been found in different populations, including Europeans, ${ }^{1,2}$ African Americans, ${ }^{3}$ and Latin Americans. ${ }^{4-6}$ A protective genetic effect in European and non-European populations has also been reported with other class II major histocompatibility complex (MHC) alleles, including HLA-DRB $1 * 01$, HLA-DRB1*10, HLA-DRB ${ }^{*} 11$, and HLA-DRB1*14.7,8

Ancestry can be estimated using nuclear ancestry informative markers (AIMs), which are insertion/deletion polymorphisms with high genomic allele frequency differences between populations. ${ }^{9}$ Furthermore, mitochondrial DNA (mtDNA) haplogroups are markers used to assess matrilineal history. ${ }^{10}$ Ancestry can be inferred more accurately using both AIMs and mtDNA haplogroups and can be used for population stratification, which is particularly important in recently admixed populations such as African Americans and Latin Americans. ${ }^{11}$

\footnotetext{
From the School of Medicine (J.T., D.C.-G., C.-M.G., S.R., F.C., A.P.), Universidad El Bosque, Bogotá, Colombia; Department of Neurology (J.T., D.C.-G., C.D.-C., L.-E.B., C.-M.G., S.R., S.C.-R.), Hospital Universitario Fundación Santa Fe de Bogotá, Bogotá, Colombia; and School of Medicine (J.T., D.C.-G., C.D.-C., L.-E.B., S.R., D.M.N., H.G.d.R.) and Human Genetics Laboratory (D.C.-G., D.M.N., W.C., M.-C.L., H.G.d.R.), Department of Biological Sciences, Universidad de Los Andes, Bogotá, Colombia.

Funding information and disclosures are provided at the end of the article. Go to Neurology.org/nn for full disclosure forms. The Article Processing Charge was paid by Universidad El Bosque.

This is an open access article distributed under the terms of the Creative Commons Attribution-NonCommercial-NoDerivatives License 4.0 (CC BY-NC-ND), which permits downloading and sharing the work provided it is properly cited. The work cannot be changed in any way or used commercially.
} 
The city of Bogotá, Colombia is located in the subtropical region near the equator. The prevalence of MS in Bogotá is 4.4 per 100,000 , making it a low-risk area. ${ }^{12}$ In contrast, MS prevalence has been reported to be higher in southern regions such as New Zealand $^{13}$ and in northern regions such as Northern Europe, ${ }^{14}$ where it can exceed 200 per 100,000 inhabitants. ${ }^{15}$

Genetic association studies of MS in Colombia and other Latin American countries are scarce. Considering the low prevalence of MS in Colombia, we hypothesized we would find a protective allele in our population. This case-control study assessed whether HLADRB1 alleles were associated with susceptibility or resistance to MS in patients from the low MS prevalence and highly admixed population of Bogotá.

METHODS Standard protocol approvals, registrations, and patient consents. The study protocol was approved by the institutional review boards of Hospital Universitario Fundación Santa Fe de Bogotá (HU-FSFB), Universidad de los Andes, and Universidad El Bosque. All participants provided written informed consent before all the procedures.

Study population. Patients diagnosed with clinically definite MS according to the $2005 \mathrm{McDonald}$ criteria ${ }^{16}$ were recruited from 2007 to 2013 at the neurology clinic of the HU-FSFB, which is a tertiary referral center that provides medical care to patients with MS from all over Colombia. A neurologist (J.T.) with expertise in MS confirmed the diagnosis in all patients. Healthy controls without past medical history of autoimmune disease or other neurologic conditions were recruited by community advertisement within 1 week of enrollment of a given case. To exclude any MS-related signs or symptoms, controls underwent neurologic examination by one of the authors. Patients included were residents of Bogotá, Colombia and were older than 18 years at the time of enrollment. The following variables were recorded for each patient: sex, age at disease onset for cases and age at enrollment for cases and controls, smoking history (ever vs never), family history of MS, disease duration, and clinical phenotypes.

DNA extraction. Venous blood was collected and DNA was extracted using the FlexiGene DNA kit (QIAGEN, Hombrechtikon, Switzerland). All samples were stored at $-20^{\circ} \mathrm{C}$ until their use, and DNA concentration was determined by spectrophotometry using NanoDrop 2000 (Thermo Fisher Scientific, Waltham, MA). Genotyping was done at the Human Genetics Laboratory of Universidad de los Andes.

Molecular assessment of AIMs. A panel of 46 AIMs was amplified in a single multiplex PCR followed by capillary electrophoresis, as previously described. ' Dye-labeled amplified fragments were separated and detected using an ABI Genetic Analyzer 3500 (Life Technologies, Carlsbad, CA), and allele calls were obtained with GeneMapper v4.1 (Life Technologies). Ancestral proportions were calculated using the STRUCTURE software v2.3.2. Considering the historical formation of Colombia, we assumed a trihybrid contribution from Native
Americans, Europeans, and Africans. ${ }^{17}$ The Human Genome Diversity Cell Line Panel was used for reference. ${ }^{9}$

mtDNA haplogroups. The mtDNA hypervariable region 1 (HVR1) was amplified by PCR with the L15840 (5'ACTTCACAACAAATCCTAATCCT3') and H16436 (5'CGGAGCGAGGAGAGTAGCAC 3') primers. Amplicons were sequenced using an ABI-PRISM Dye Terminator Cycle sequencing system (Applied Biosystems, Foster City, CA). Sequence variants were determined between mtDNA nucleotides HVR1 (16024-16365) by comparing them with the revised Cambridge Reference Sequence (GenBank accession no. NC_012920.1) using HaploSearch software. ${ }^{18}$ The haplogroup classification was inferred using HaploGrep software. ${ }^{19}$

HLA typing. The samples were genotyped at the HLA-DRB1 gene locus using the HLA-DRB sequence-specific primer PCR kit (Biotest AG, Dreieich, Germany). Each reaction included primers for a fragment from the human growth hormone gene as internal controls. In the final data set, the alleles were resolved into 13 allele groups. For more details, see the e-methods at Neurology.org/nn.

Statistical analysis. Descriptive statistics, including mean, median, SD, and interquartile range, were used to characterize the study population. Group comparisons of demographic and clinical characteristics were performed using Z-test or Wilcoxon rank sum test where appropriate. When comparing proportions of categorical variables, a Z-proportion test, $\chi^{2}$ test, and Fisher exact test were used as appropriate. A $p$ value $<0.05$ was considered statistically significant.

To assess population stratification, a k-means cluster analysis of ancestry data was performed. Odds ratios (ORs) were used to reflect effect sizes of MS risk. A stepwise selection logistic regression analysis was performed starting with a full model, which had a significant level of addition and removal of 0.1 and 0.25 , respectively. To control for type I error after 13 different tests, the Bonferroni correction was applied, and a $p$ value $<0.004$ was considered statistically significant. The Hosmer-Lemeshow statistic and deviance were used to measure the goodness of fit of the model to the data set. Hardy-Weinberg equilibrium was calculated using asymptotic tests $^{20}$ (STATA v12.0 software; StataCorp, College Station, TX). All analyses were performed using Stata 11 SE.

RESULTS A total of 103 patients and 202 controls were enrolled. However, we included in the analysis only the 100 patients and 200 controls in whom mtDNA, AIMs, and HLA genotyping was successful. Demographic data of the study population are shown in table 1 .

mtDNA haplogroups and MS. A total of $12 \mathrm{mtDNA}$ haplogroups were identified in the patients studied. The Amerindian haplogroup A was the most common in our population; it was present in $36 \%$ of the patients and $45 \%$ of the healthy controls. The Amerindian haplogroup B was present in $24 \%$ of the patients and $26.5 \%$ of the healthy controls. Amerindian haplogroups $\mathrm{C}$ and $\mathrm{D}$ were each present in $12 \%$ in the patients; haplogroup $\mathrm{C}$ was present in $9.5 \%$ of controls and haplogroup $\mathrm{D}$ was present in $7.5 \%$ of controls. The African haplogroup $L$ was found in $5 \%$ of the patients and $6.5 \%$ of the healthy controls. The European haplogroups H, J, T, U, V, 
Table 1 Clinical and demographic features of the enrolled participants

\begin{tabular}{|c|c|c|c|}
\hline & MS $(n=100)$ & $\begin{array}{l}\text { Controls } \\
(n=200)\end{array}$ & p Value \\
\hline Sex, female, $n(\%)$ & 70 (70) & 167 (83.5) & $0.0068^{\circ}$ \\
\hline Age, y, median (IQR) & $39(30.5-48.5)$ & $38(29-46)$ & $0.0836^{b}$ \\
\hline Age at onset, $y$, median (IQR) & $30(23-29)$ & - & \\
\hline Age at disease diagnosis, y, median (IQR) & $32(25-41)$ & - & \\
\hline Smoking history, $\mathrm{n}(\%)$ & 39 (39) & $61(30.5)$ & $0.1410^{\circ}$ \\
\hline Family history of MS, $n(\%)$ & $3(3)$ & $3(1.5)$ & $0.3817^{2}$ \\
\hline \multicolumn{4}{|l|}{ Clinical phenotypes, n (\%) } \\
\hline Relapsing-remitting & $81(81)$ & -- & \\
\hline Secondary progressive & 14 (14) & -- & \\
\hline Primary progressive & $4(4)$ & -- & \\
\hline Progressive-relapsing & $1(1)$ & -- & \\
\hline
\end{tabular}

Abbreviations: IQR = interquartile range; MS = multiple sclerosis.

Smoking history: ever vs never. Family history is defined as presence of primary or secondary relatives with MS.

${ }^{a} \chi^{2}$ test.

${ }^{\mathrm{b}}$ Wilcoxon rank sum test.
34.28\% Amerindian, and $11.01 \%$ African ancestry. Cluster analysis revealed no differences among patients and controls when comparing the European $(p=0.872)$, Amerindian $(p=0.992)$, or African $(p=0.204)$ ancestry contribution.

Association analysis for HLA alleles. No deviation from Hardy-Weinberg equilibrium was seen in the data set $(p>0.01)$. Results of the stepwise selection modeling identified the following variables as covariates in the multivariate logistic regression model: age at onset of symptoms (age at enrollment for the healthy controls), sex, smoking history, and ancestry (European and Amerindian proportion). After controlling for admixture, the association between the multiallelic HLADRB1 and MS was confirmed. HLA-DRB1*04 allele was the most frequent in both patients $(42 \%)$ and controls (42.5\%), whereas HLA-DRB1*09 and HLA-DRB $1 * 12$ alleles were the least frequent (see table 2). HLA-DRB1* 15 was present in $31 \%$ of cases and $13.5 \%$ of controls, whereas HLADRB1*14 was present in $5 \%$ of cases and $15.5 \%$ of controls. The presence of HLA-DRB1*15 was associated with MS onset in the univariate model $(\mathrm{OR}=2.87, p<0.001)$ and multivariate models $(\mathrm{OR}=3.05, p<0.001)$. HLA-DRB1 $* 14$ was not associated with $\mathrm{MS}$ in the univariate analysis $(\mathrm{OR}=$ $0.28, p=0.012$ ) but reached statistical significance in the multivariate model and was confirmed as a protective factor $(\mathrm{OR}=0.16, p=0.001)$ in our population. No significant association was found for other HLA-DRB1 alleles. whereas healthy controls had $54.71 \%$ European,

AIMs and MS. Ancestry estimation revealed that patients with MS had on average 55.03\% European, $32.55 \%$ Amerindian, and $12.42 \%$ African ancestry,

and $\mathrm{X}$ and the Asian haplogroup $\mathrm{Y}$ were less commonly found in our population and accounted for $5 \%$. However, the distribution of mtDNA logroups among patients and healthy controls was not different $(p=0.218)$.

rence

\begin{tabular}{|c|c|c|c|c|c|c|c|c|}
\hline \multicolumn{9}{|c|}{ Table 2 Association of HLA-DRB1 alleles and MS } \\
\hline \multirow[b]{2}{*}{ HLA-DRB1 allele } & \multirow{2}{*}{$\begin{array}{l}\text { MS, n (\%) } \\
(n=100)\end{array}$} & \multirow{2}{*}{$\begin{array}{l}\text { Controls, } n(\%) \\
(n=200)\end{array}$} & \multicolumn{3}{|c|}{ Univariate analysis } & \multicolumn{3}{|c|}{ Multivariate analysis } \\
\hline & & & OR & $95 \% \mathrm{Cl}$ & $p$ Value & $O R^{a}$ & $95 \% \mathrm{Cl}$ & $p$ Value \\
\hline$* 01$ & $14(14)$ & 25 (12.5) & 1.13 & $0.56-2.30$ & 0.716 & 1.25 & $0.59-2.67$ & 0.549 \\
\hline *03 & $21(21)$ & $36(18)$ & 1.21 & $0.66-2.20$ & 0.533 & 1.25 & $0.65-2.38$ & 0.492 \\
\hline$* 04$ & $42(42)$ & 85 (42.5) & 0.97 & $0.60-1.59$ & 0.934 & 1.00 & $0.59-1.70$ & 0.972 \\
\hline$* 07$ & $17(17)$ & 37 (18.5) & 0.90 & $0.47-1.69$ & 0.750 & 0.99 & $0.50-1.96$ & 0.983 \\
\hline$* 08$ & 9 (9) & $26(13)$ & 0.66 & $0.29-1.47$ & 0.312 & 0.61 & $0.25-1.45$ & 0.271 \\
\hline$* 09$ & $1(1)$ & 4 (2) & 0.49 & $0.05-4.48$ & 0.532 & 0.27 & $0.02-2.70$ & 0.269 \\
\hline$* 10$ & 3 (3) & 5 (2.5) & 1.20 & $0.28-5.15$ & 0.800 & 1.87 & $0.40-8.60$ & 0.419 \\
\hline$* 11$ & $8(8)$ & 29 (14.5) & 0.51 & $0.22-1.16$ & 0.112 & 0.51 & $0.21-1.23$ & 0.138 \\
\hline *12 & $1(1)$ & $4(2)$ & 0.49 & $0.05-4.48$ & 0.532 & 0.27 & $0.02-2.78$ & 0.275 \\
\hline$* 13$ & $24(24)$ & 43 (21.5) & 1.15 & $0.65-2.03$ & 0.624 & 1.11 & $0.60-2.06$ & 0.719 \\
\hline$* 14$ & 5 (5) & 31 (15.5) & 0.28 & $0.10-0.76$ & 0.012 & 0.16 & $0.05-0.46$ & 0.001 \\
\hline$* 15$ & 31 (31) & 27 (13.5) & 2.87 & $1.60-5.17$ & $<0.00$ & 3.05 & $1.62-5.71$ & $<0.001$ \\
\hline$* 16$ & 9 (9) & 17 (8.5) & 1.06 & $0.45-2.48$ & 0.885 & 1.44 & $0.58-3.56$ & 0.425 \\
\hline
\end{tabular}

Abbreviations: $\mathrm{Cl}=$ confidence interval; $\mathrm{MS}=$ multiple sclerosis; $\mathrm{OR}=$ odds ratio.

${ }^{a}$ Adjusted OR after controlling for the following covariates: age at onset of symptoms (age at enrollment for the healthy controls), sex, smoking history, and ancestry (European and Amerindian proportion). 
DISCUSSION In this study exploring the association between HLA alleles and susceptibility to MS in Colombia, we also describe additional genetic data such as AIMs and mtDNA haplogroups. Our results were consistent with previously reported HLA-DRB1 allelic associations. Although HLA-DRB1*15 allele has been classically reported as a risk factor for MS in European descendants, ${ }^{1}$ it has also been found in other Caucasian, ${ }^{5}$ African, ${ }^{3}$ and Latin American populations, including studies from Brazil, ${ }^{5}$ Argentina, ${ }^{21}$ and Martinique. $^{22}$ This allele has been shown to increase not only disease susceptibility ${ }^{23}$ but also morbidity. ${ }^{24}$ In the univariate analysis, we found a significant association between HLA-DRB1*15 and MS risk. Furthermore, this finding was sustained in the multivariate analysis and survived Bonferroni correction, conferring a 3-fold increased risk of MS among our population. Previous studies have found a similar effect size for HLA-DRB $1 * 15 .{ }^{25}$

HLA-DRB $1 * 14$ allele exerts a protective effect in our population. The role of HLA-DRB $1 * 14$ observed in this study has been reported in other countries, such as $\mathrm{Canada}^{7}$ and China. ${ }^{7}$ Some studies have shown that its protective effect is strong enough to counteract the risk conferred by the presence of HLA-DRB $1 * 15$ and to influence the regional prevalence of MS.7

A previous study in the Antioquia region of Colombia also reported a significant association between HLA-DRB1*15 allele and MS. This study also identified HLA-DRB $1 * 01$ allele as a risk factor and HLA-DRB ${ }^{*} 07$ allele as a protective one. ${ }^{26}$ However, we did not find these associations in our population. This difference could be partially attributed to our larger sample size and the statistical methods used in our study (e.g., adjusting for multiple confounders related to demographic and genetic characteristics).

The clinical and demographic characteristics of our patients were fairly consistent with those previously reported in other countries. ${ }^{27}$ The Colombian population is thought to be genetically substructured, with different proportions of European, Amerindian, and African influxes depending on the region. AIM analysis showed that the population of Bogotá has a significant genetic admixture with predominant European and Amerindian ancestry. African ancestry was less frequent. Similar genetic composition has been found in other Colombian populations and can be explained by Colombia's colonization and slave trade history. ${ }^{28}$ In addition, our population has the same ethnic origin as that of other Colombian groups, as the mtDNA analysis did not differ from previous studies. ${ }^{29}$

AIMs are mainly used to estimate ancestry proportions, allowing for assessment of the structure in admixed populations, and mtDNA haplogroups reflect a clear pattern of matrilineal historical events that are not obscured by the factors of recombination. Therefore, it has been suggested that using both genetic markers can improve the accuracy of the reconstitution of genetic ancestry among certain populations, particularly those that are highly admixed, like most in Latin America.'

AIMs can be used to perform genetic matching or to correct substructure effects in case-control studies. ${ }^{9}$ Because there were no differences in AIMs and mtDNA haplogroups between patients and controls, we can assume that our study population is not stratified and that the observed associations with HLADRB1 alleles are not spurious.

Because previous studies conducted in Latin America $^{26,30}$ have consistently reported significant associations between the $H L A-D R B 1$ gene and MS risk, we did not include other protective and predisposing alleles such as HLA-A*02:01 and HLA-DQB1*06:02, respectively, which would have allowed us to more comprehensively evaluate their genetic influence on MS susceptibility in Colombia. Furthermore, it would have been clinically relevant to explore the complex interaction between genetic expression, disease severity, and environmental factors; however, this was outside the scope of this study and is the subject of ongoing investigation in our group.

The increased number of HLA alleles reported across different ancestral groups has led to the conclusion that immunologically relevant genes across the $\mathrm{MHC}$ region dominate the genetic contribution of MS. However, additional efforts must be made to validate current and future findings in genetic-matched populations using AIMs and mtDNA haplogroups. This study provides evidence indicating that HLADRB $1 * 15$ allele confers susceptibility to MS whereas HLA-DRB $1 * 14$ allele exerts resistance to MS in the low prevalence and highly admixed population of Bogotá, Colombia.

\section{AUTHOR CONTRIBUTIONS}

Jaime Toro: drafting/revising the manuscript for content, including medical writing for content; study concept and design; analysis and interpretation of data; obtaining funding; and study supervision. David Cuellar-Giraldo: drafting/revising the manuscript for content, including medical writing for content; study concept; and acquisition, analysis, and interpretation of data. Camilo Díaz-Cruz: drafting/revising the manuscript for content, including medical writing for content; study concept; acquisition, analysis, and interpretation of data; and statistical analysis. Lisseth-Estefania Burbano: drafting/revising the manuscript for content, including medical writing for content; study concept; and acquisition, analysis, and interpretation of data. Claudia-Marcela Guío: drafting/revising the manuscript for content, including medical writing for content; study concept; and acquisition, analysis, and interpretation of data. Saúl Reyes: drafting/revising the manuscript for content, including medical writing for content; study concept; and acquisition, analysis, and interpretation of data. Fabián Cortes: analysis and interpretation of the data. Simón CárdenasRobledo: drafting/revising the manuscript for content, including medical writing for content; study concept; and acquisition, analysis, and 
interpretation of data. Diana M. Narváez: drafting/revising the manuscript for content, including medical writing for content; study concept; and acquisition, analysis, and interpretation of data. Wilmer Cárdenas: design and conceptualization of the study. Alexandra Porras: analysis and interpretation of the data. María-Claudia Lattig: design and conceptualization of the study. Helena Groot de Restrepo: drafting/revising the manuscript for content, including medical writing for content, and design and conceptualization of the study.

\section{STUDY FUNDING}

Universidad el Bosque, Hospital Universitario Fundación Santa Fe de Bogotá, and Universidad de los Andes.

\section{DISCLOSURE}

J. Toro is associate editor of NEJM Journal Watch Neurology and is an editorial board member for Multiple Sclerosis and Related Disorders. D. Cuellar-Giraldo, C. Díaz-Cruz, L.-E. Burbani, C.-M. Guío, S. Reyes, F. Cortes, S. Cárdenas-Robledo, D.M. Narváez, W. Cárdenas, A. Porras, M.-C. Lattig, and H. Groot de Restrepo report no disclosures. Go to Neurology.org/nn for full disclosure forms.

Received August 21, 2015. Accepted in final form November 3, 2015.

\section{REFERENCES}

1. Schmidt H, Williamson D, Ashley-Koch A. HLA-DR15 haplotype and multiple sclerosis: a HuGE review. Am J Epidemiol 2007;165:1097-1109.

2. Hafler DA, Compston A, Sawcer S, et al. Risk alleles for multiple sclerosis identified by a genomewide study. N Engl J Med 2007;357:851-862.

3. Isobe $\mathrm{N}$, Gourraud PA, Harbo HF, et al. Genetic risk variants in African Americans with multiple sclerosis. Neurology 2013;81:219-227.

4. Alcina A, Abad-Grau Mdel M, Fedetz M, et al. Multiple sclerosis risk variant HLA-DRB1*1501 associates with high expression of DRB1 gene in different human populations. PLoS One 2012;7:e29819.

5. Brum DG, Barreira AA, Louzada-Junior P, MendesJunior CT, Donadi EA. Association of the HLA-DRB1*15 allele group and the DRB1*1501 and DRB1*1503 alleles with multiple sclerosis in White and Mulatto samples from Brazil. J Neuroimmunol 2007;189:118-124.

6. Alves-Leon SV, Papais-Alvarenga R, Magalhães M, et al. Ethnicity-dependent association of HLA DRB1-DQA1DQB1 alleles in Brazilian multiple sclerosis patients. Acta Neurol Scand 2007;115:306-311.

7. Ramagopalan SV, Morris AP, Dyment DA, et al. The inheritance of resistance alleles in multiple sclerosis. PLoS Genet 2007;3:1607-1613.

8. Zhang Q, Lin CY, Dong Q, Wang J, Wang W. Relationship between HLA-DRB1 polymorphism and susceptibility or resistance to multiple sclerosis in Caucasians: a metaanalysis of non-family-based studies. Autoimmun Rev 2011;10:474-481.

9. Pereira R, Phillips C, Pinto N, et al. Straightforward inference of ancestry and admixture proportions through ancestry-informative insertion deletion multiplexing. PLoS One 2012;7:e29684.

10. Cardena MM, Ribeiro-Dos-Santos Â, Santos S, Mansur AJ, Pereira AC, Fridman C. Assessment of the relationship between self-declared ethnicity, mitochondrial haplogroups and genomic ancestry in Brazilian individuals. PLoS One 2013;8:e62005.

11. Liu Y, Nyunoya T, Leng S, Belinksy SA, Tesfaigzi Y, Bruse S. Softwares and methods for estimating genetic ancestry in human populations. Hum Genomics 2013;7: 1. doi: 10.1186/1479-7364-7-1.

12. Toro J, Sarmiento OL, Díaz Del Castillo A, et al. Prevalence of multiple sclerosis in Bogotá, Colombia. Neuroepidemiology 2007;28:33-38.

13. Pugliatti M, Sotgiu S, Rosati G. The worldwide prevalence of multiple sclerosis. Clin Neurol Neurosurg 2002;104: 182-191.

14. Kurtzke JF. Epidemiology of multiple sclerosis. Does this really point toward an etiology? Lectio Doctoralis. Neurol Sci 2000;21:383-403.

15. Koch-Henriksen N, Sørensen PS. The changing demographic pattern of multiple sclerosis epidemiology. Lancet Neurol 2010;9:520-532.

16. Polman $\mathrm{CH}$, Reingold SC, Edan G, et al. Diagnostic criteria for multiple sclerosis: 2005 revisions to the “McDonald Criteria”. Ann Neurol 2005;58:840-846.

17. Bedoya G, Montoya P, Garcia J, et al. Admixture dynamics in Hispanics: a shift in the nuclear genetic ancestry of a South American population isolate. Proc Natl Acad Sci U S A 2006;103:7234-7239.

18. Fregel R, Delgado S. HaploSearch: a tool for haplotypesequence two-way transformation. Mitochondrion 2011; 11:366-367.

19. Kloss-Brandstätter A, Pacher D, Schönherr S, et al. HaploGrep: a fast and reliable algorithm for automatic classification of mitochondrial DNA haplogroups. Hum Mutat 2011;32:25-32.

20. Cleves MA. Hardy-Weinberg equilibrium tests and allele frequency estimation. STATA Tech Bull 1999;48:34-37.

21. Patrucco L, Larriba J, Redal M, et al. HLA-DRB1 and multiple sclerosis in Argentina. Eur J Neurol 2009;16: 427-429.

22. Quelvennec E, Bera O, Cabre P, et al. Genetic and functional studies in multiple sclerosis patients from Martinique attest for a specific and direct role of the HLA-DR locus in the syndrome. Tissue Antigens 2003;61:166-171.

23. Oksenberg JR. Decoding multiple sclerosis: an update on genomics and future directions. Expert Rev Neurother 2013;13(12 suppl):11-19.

24. Vasconcelos CCF, Fernández O, Leyva L, et al. Does the DRB1*1501 allele confer more severe and faster progression in primary progressive multiple sclerosis patients? HLA in primary progressive multiple sclerosis. J Neuroimmunol 2009;214:101-103.

25. Sawcer S, Franklin RJM, Ban M. Multiple sclerosis genetics. Lancet Neurol 2014;13:700-709.

26. Rojas OL, Rojas-Villarraga A, Cruz-Tapias P, et al. HLA class II polymorphism in Latin American patients with multiple sclerosis. Autoimmun Rev 2010;9:407-413.

27. Toro J, Cárdenas S, Martínez CF, et al. Multiple sclerosis in Colombia and other Latin American countries. Mult Scler Relat Disord 2013;2:80-89.

28. Galanter JM, Fernandez-Lopez JC, Gignoux CR, et al. Development of a panel of genome-wide ancestry informative markers to study admixture throughout the Americas. PLoS Genet 2012;8:e1002554.

29. Yunis JJ, Yunis EJ. Mitochondrial DNA (mtDNA) haplogroups in 1526 unrelated individuals from 11 Departments of Colombia. Genet Mol Biol 2013;36:329-335.

30. Alaez C, Corona T, Ruano L, et al. Mediterranean and Amerindian MHC class II alleles are associated with multiple sclerosis in Mexicans. Acta Neurol Scand 2005;112: 317-322. 


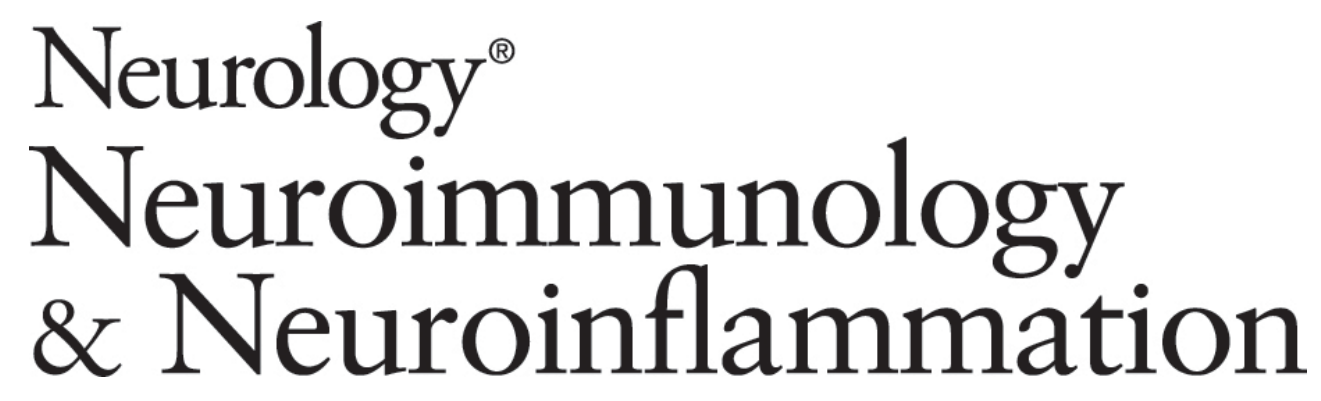

HLA-DRB1*14 is a protective allele for multiple sclerosis in an admixed Colombian population

Jaime Toro, David Cuellar-Giraldo, Camilo Díaz-Cruz, et al.

Neurol Neuroimmunol Neuroinflamm 2016;3;

DOI 10.1212/NXI.0000000000000192

This information is current as of December 24, 2015

Neurol Neuroimmunol Neuroinflamm is an official journal of the American Academy of Neurology.

Published since April 2014, it is an open-access, online-only, continuous publication journal. Copyright $\odot$ 2015 American Academy of Neurology. All rights reserved. Online ISSN: 2332-7812.

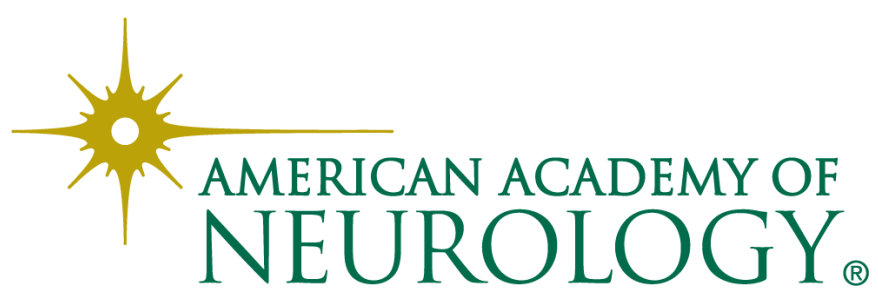




\section{Updated Information \&} Services

\section{Supplementary Material}

References

Subspecialty Collections

\section{Permissions \& Licensing}

Reprints including high resolution figures, can be found at: http://nn.neurology.org/content/3/1/e192.full.html

Supplementary material can be found at: http://nn.neurology.org/content/suppl/2015/12/24/3.1.e192.DC1

This article cites 30 articles, 1 of which you can access for free at: http://nn.neurology.org/content/3/1/e192.full.html\#\#ref-list-1

This article, along with others on similar topics, appears in the following collection(s):

Association studies in genetics

http://nn.neurology.org//cgi/collection/association_studies_in_genetics Case control studies

http://nn.neurology.org//cgi/collection/case_control_studies

Multiple sclerosis

http://nn.neurology.org//cgi/collection/multiple_sclerosis

Risk factors in epidemiology

http://nn.neurology.org//cgi/collection/risk_factors_in_epidemiology

Information about reproducing this article in parts (figures,tables) or in its entirety can be found online at:

http://nn.neurology.org/misc/about.xhtml\#permissions

Information about ordering reprints can be found online: http://nn.neurology.org/misc/addir.xhtml\#reprintsus

Neurol Neuroimmunol Neuroinflamm is an official journal of the American Academy of Neurology.

Published since April 2014, it is an open-access, online-only, continuous publication journal. Copyright $\odot$ 2015 American Academy of Neurology. All rights reserved. Online ISSN: 2332-7812.

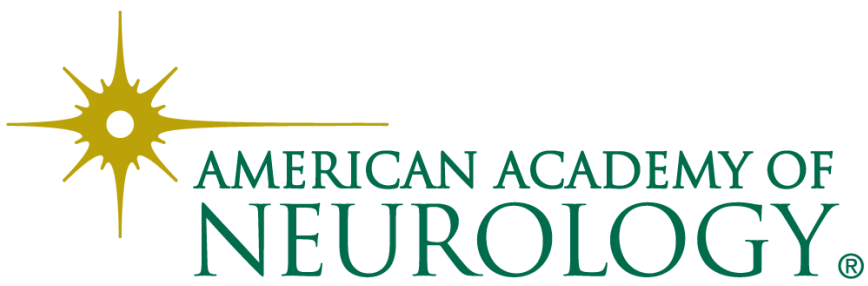

